
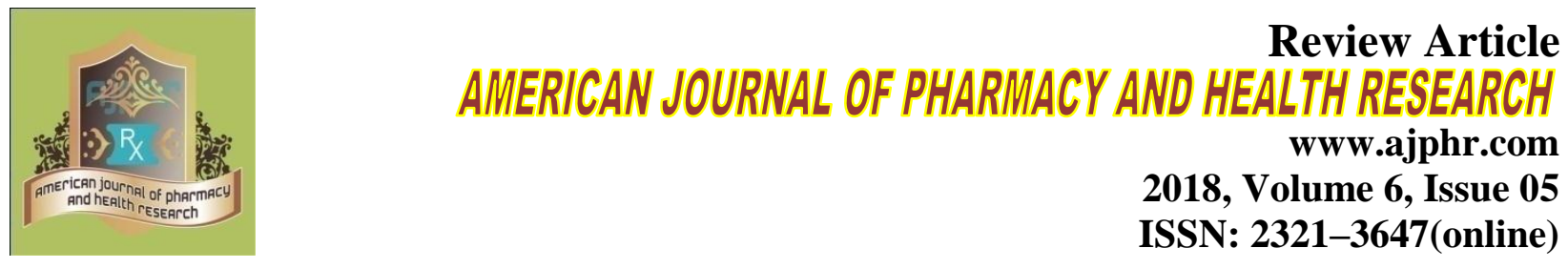

\title{
A Review of Tablet in Tablet Vitamin D3 Formulation Techniques
}

\author{
P. Inigo*, R.Ramprasad ${ }^{1}$, S.R.Senthilkumar ${ }^{1}$, N. Venkateshan ${ }^{2}$ \\ Department of Pharmacy, Arulmigu Kalasaligam College of Pharmacy
}

\section{ABSTRACT}

The studies is to review formulated core tablets (tablet in tablet) and difficulty in the formulation and evaluation. Numerous techniques are used overcome the problem of stability. The tablet coating have number of advantages like masking odor, taste, color of the drug, providing physical and chemical protection to drug, Protecting drug from the gastric environment. Most of the tablets are instable in gastro industrial tract. Coated, encapsulation, capsules instructed tablet, gel coated tablet. Vitamin D3 containing cholecalciferol (made from 7-dehydrocholesterol in the skin). Several forms (vitamins) of vitamin D exist. The two major forms are vitamin $\mathrm{D}_{2}$ or ergocalciferol, and vitamin $\mathrm{D}_{3}$ or cholecalciferol; vitamin $\mathrm{D}$ without a subscript refers to either $\mathrm{D}_{2}$ or $\mathrm{D}_{3}$ or both. Vitamin D3 contain natural foods like Fatty fish, like tuna, mackerel, and salmon Foods fortified with vitamin D, like some dairy products, orange juice, soy milk, and cereals, Beef liver, Cheese, Egg yolks. Industrial production encovndred several evaluation error like weight variation, hardness, friability, thickness, solubility, disintegration test. Here dissolution test not necessary because vitD3 was a supplementary USP not recognized. Nutrients do not work alone, and when it comes to taking vitamin D, its important that you take any compound and vitamin D together and not JUST vitamin $\mathrm{d}$ alone in large doses as this can lead to what people BELIEVE are vitamin d side effects.

Keywords: Vitamin D3, cholecalciferol, coated tablet 


\section{INTRODUCTION}

Vitamin D3(cholecalciferol) is derived from 7-dehyrocholesterol and involved in bone health. Scientists have recognized that, depression, back pain, cancer, both insulin resistance and preeclampsia during pregnancy, impaired immunity and macular degeneration are directly linked to the Vitamin D3 deficiency ${ }^{1}$. Inadequate Vitamin D3 may cause secondary hyperparathyroidism that increases the risk of osteoporosis and fractures and change the regulatory mechanisms of parathyroid hormone $(\mathrm{PTH})^{2,3}$. Other types of condition such as high blood pressure, fibromyalgia, diabetes, multiple sclerosis, rheumatoid arthritis has been linked to the low levels of Vitamin D3 $3^{4,5}$. Vitamin D3 deficiency is responsible psychiatric and neurologic disorders and associated with low mood ${ }^{6}$.

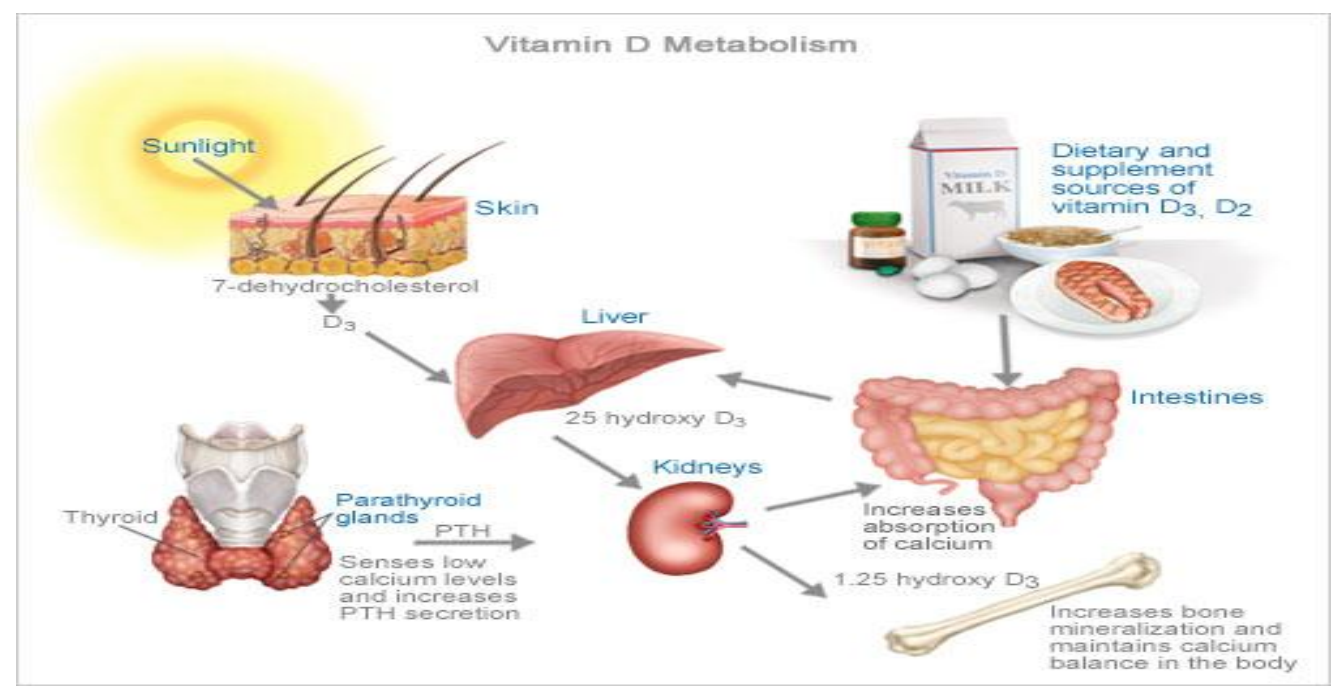

Figure 1: Vitamin D metabolism

\section{ORAL TABLETS:}

Standard compressed tablets e.g. Paracetamol tablet' Multiple compressed tablets' I. Compression coated tablet- sugar coated tablet, Film coated tablet, Gelatin coated tablet, Enteric coated tablet II. Layered tablet III. Inlay tablet Targeted table ${ }^{7,8,9}$.

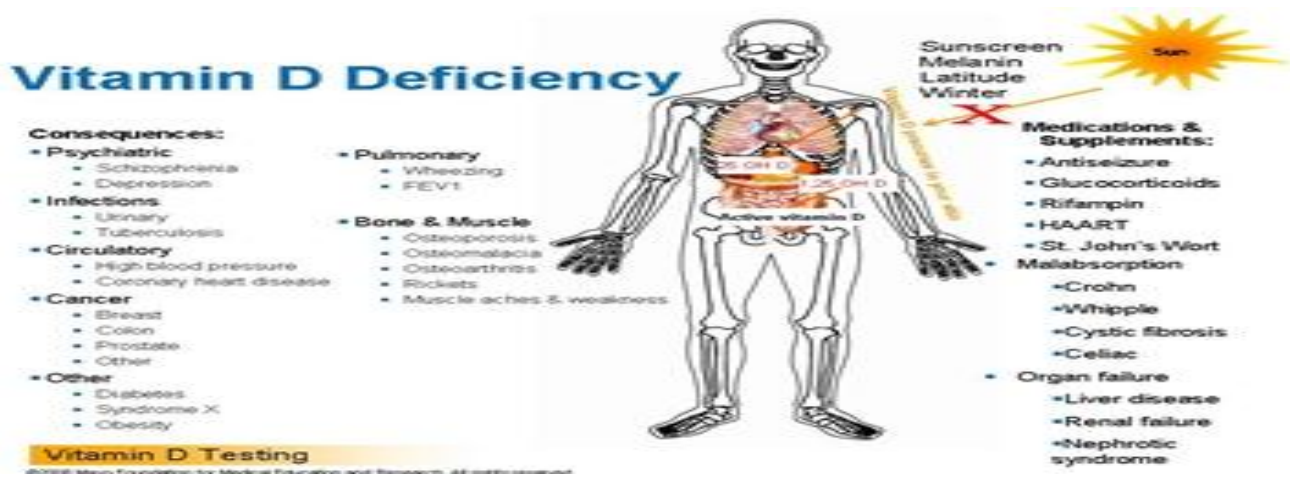

Figure: 2 vitamin D Deficiency 


\section{Floating tablet' II. Colon targeting tablet \\ Different types of Tablets:}

Tablets ingested orally: 1. Compressed tablet, e.g. Paracetamol tablet 2. Multiple compressed tablet 3. Repeat action tablet 4. Delayed release tablet, e.g. Enteric coated Bisacodyl tablet 5. Sugar coated tablet, e.g. Multivitamin tablet 6. Film coated tablet, e.g. Metronidazole tablet 7. Chewable tablet, e.g. Antacid tablet ${ }^{10,11,12}$. Tablets used in oral cavity: 1. Buccal tablet, e.g. Vitamin-c tablet 2. Sublingual tablet, e.g. Vicks Menthol tablet 3. Troches or lozenges 4. Dental cone $^{13,14}$. Tablets administered by other route: 1. Implantation tablet 2. Vaginal tablet, e.g. Clotrimazole tablet (D) ${ }^{15,16}$. Tablets used to prepare solution: Effervescent tablet, e.g. Dispirin tablet (Aspirin) 2. Dispensing tablet, e.g. Enzyme tablet (Digiplex) 3. Hypodermic tablet 4. Tablet triturates e.g. Enzyme tablet (Digiplex) ${ }^{17,18}$.

\section{Tablet-in-tablet technology:}

Tablets are indeed the most popular solid dosage form for oral administration. One category of tablet formulations that has gained remarkable importance in drug therapeutics owing to various benefits it offers is controlled or modified release formulations ${ }^{19,20,21}$. Although less popular, tablet-in a tablet technology (see Fig 1) gained increased interest in the recent years for creating modified released products ${ }^{22,23}$. It involves the compaction of granular materials around a preformed tablet core using specially designed tableting equipment. Compression coating is a dry process ${ }^{24,25,26}$. This type of tablet (compression coated tablet) has two parts, internal core and surrounding coat ${ }^{27,28}$. The core is small porous tablet and prepared on one turret. After tablet core manufacture it is transferred (centrally positioned) to another slightly larger die that is partially filled with coating powder. More coating powder is filled on the top of the core and compressed again resulting in tablet with in tablet. Mechanically, it is a complex process, as the tablet may be tilted when transferred to the second die cavity. Mostly, the coat is water soluble and disintegrates easily after swallowing, in order to achieve immediate release product. This tablet readily lend itself in to a repeat action tablet as the outer layer provides the initial dose while the inner core release the drug later on. But, when the core quickly releases the drug, entirely different blood level is achieved with the risk of over dose toxicity. To avoid immediate release of both the layers, the core tablet is coated with enteric polymer so that it will not release the drug in stomach while, the first dose is added in outer sugar coating. Even so, coating operation requires interpretation while manufacturing and dawdling the manufacturing process. Sometimes, inner core may be of liquid formulation to provide immediate release of core after the coat gets dissolved ${ }^{29,30}$. Tablet coating is the key step involved in the manufacturing of 
tablets having controlled release, delayed release profiles. The tablet coating have number of advantages like masking odor, taste, color of the drug, providing physical and chemical protection to drug, Protecting drug from the gastric environment. Tablets are usually coated in horizontal rotating pan with coating solution is either directly poured or sprayed on to them. The amount of coating on the surface of a tablet is critical to the effectiveness of the oral dosage form. Recent trends in tablet coating focuses on overcoming disadvantage of solvent based coating. This review concerns with the coating process, equipment's involved, coated tablets evaluation and specialized coating techniques. Tablets are usually coated in horizontal rotating pans with the coating sprayed onto the free surface of the tablet bed. Tablets must have a coating mass that lies within a prescribed range with very little inter-and intra-tablet coating variability. Using the Discrete Element Method (DEM) tablet coating can be simulated on the computer $31,32,33$.

\section{Initial wetting}

The tablet surface wets as it becomes immersed in aqueous media. The polymer then begins to hydrate forming a gel layer. Drug near the surface of the tablet is released.

Expansion of gel layer As water permeates into the tablet, the polymer swells causing an increase in size. The soluble drug diffuses through the gel layer. The dry core also contributes to the swelling.

\section{Tablet Erosion}

Outer polymer layer becomes fully hydrated which eventually dissolves into the gastric fluids. Water continues to permeate towards the tablet core.

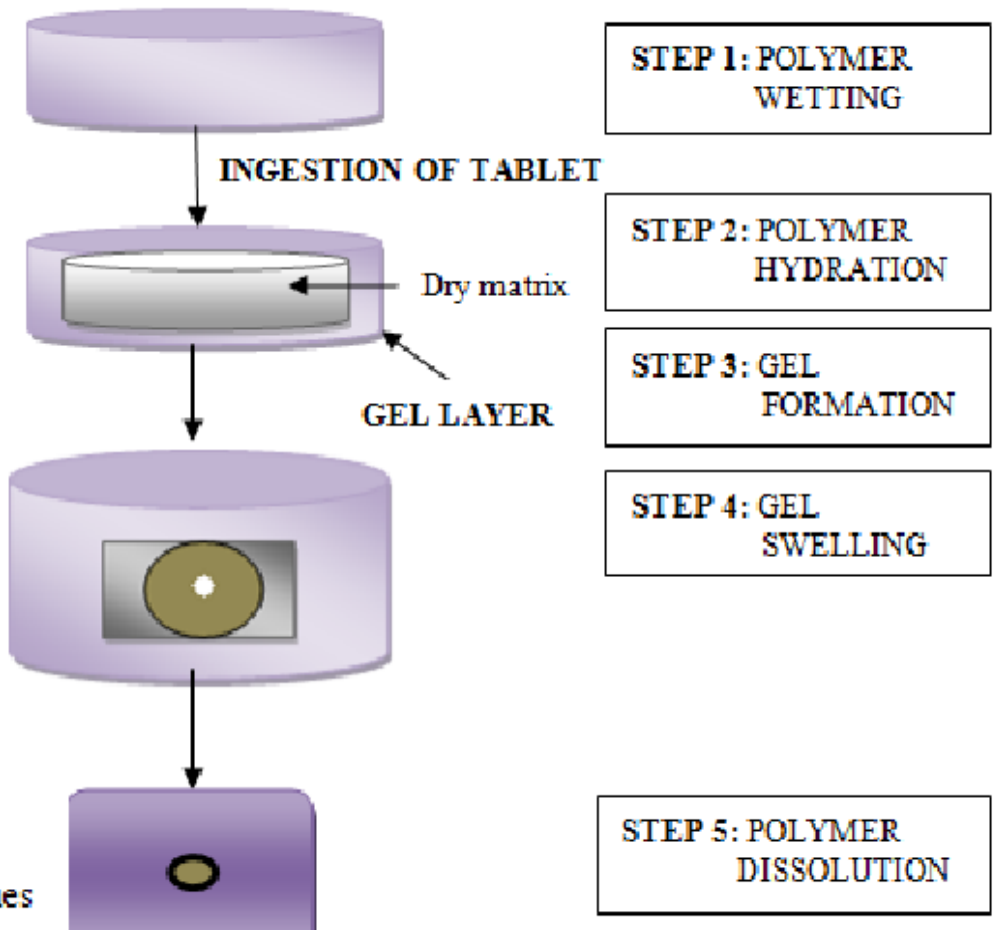

SOLUBLE DRUG

Released primarily by DIFFUSION through the gel layer.
INSOLUBLE DRUG

Released primarily by tablet

EROSION.

Figure 3: Formulation Tablet in Tablet 


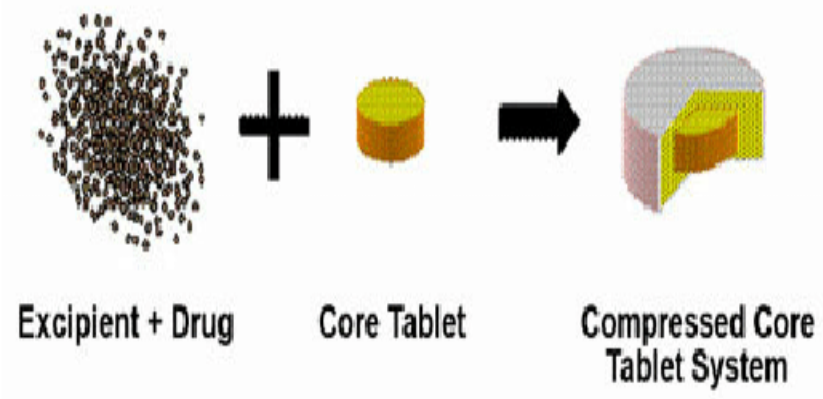

\section{Figure :4 Compressed Core Tablet System}

Simulation data provide the position, velocity and orientation of each tablet within the coater allowing accurate measurements of the time and orientation that each tablet spends exposed to the coating spray. The blend was compressed on a single punch machine, tablets were subjected to various tests (weight variation, diameter and thickness, hardness, disintegration and assay of the drug) and the results were also in compliance with the official specifications ${ }^{34,35}$.

(a)

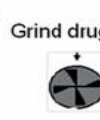

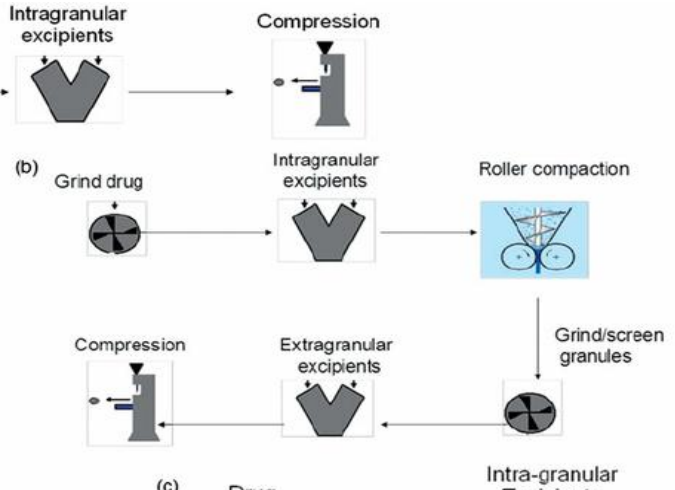

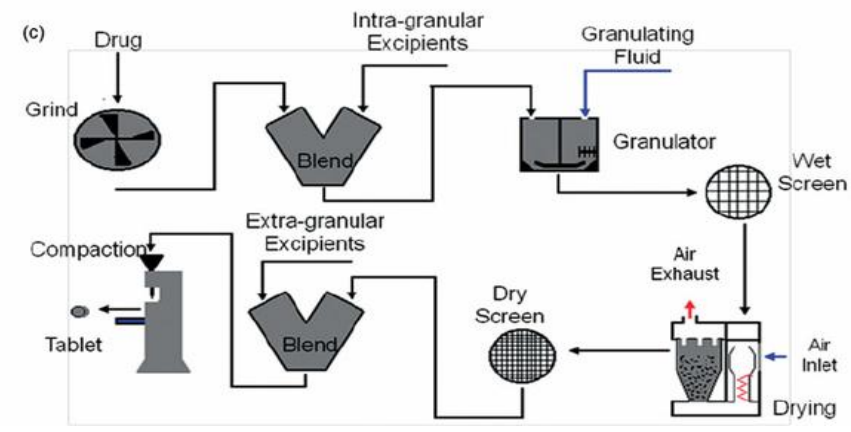

Figure: 5 Tablets Various Compression 
A

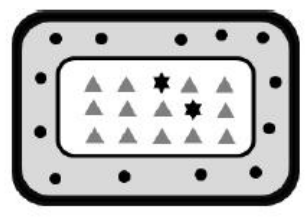

B

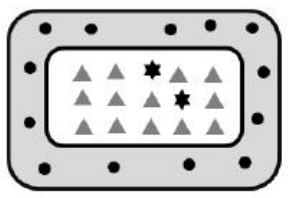

C

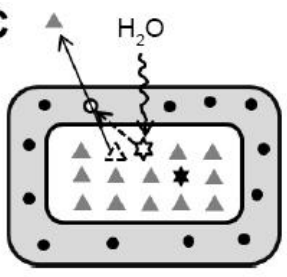

D

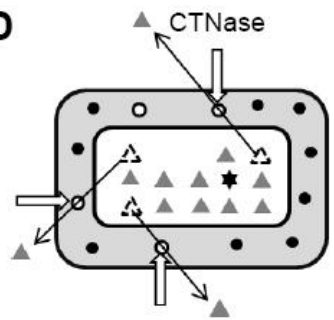

\section{$\square$ Enteric coating $\square$ CTN-dispersed polymeric subcoating $\square$ core tablet \\ - Chitosan (CTN) ODigested CTN $\quad$ Citric acid (CA) « Dissolved CA $\triangle$ Drug}

Figure I Stepwise illustration of DL-CDDS as a platform for colon targeting.

Notes: (A) In the stomach, the outermost enteric coating layer inhibits drug release; (B) in the small intestine, the inner CTN-dispersed polymeric subcoating layer impedes drug release; $(\mathbf{C})$ in the colon, water infiltrates the core tablet and dissolves CA, resulting in microclimate acidification and pore generation to some extent; (D) in the latter part of the colon, under the influence of microflora, such as CTNase, a number of microporous channels are formed by enzymatic CTN digestion, thus facilitating drug release.

Abbreviations: DL-CDDS, double layer-coated colon-specific drug delivery system; CTN, chitosan; CTNase, chitosanase.

\section{Figure : 6 Core Tablet Designed}

All the physical properties studied indicated that all excipients are good pharmaceutical excipients in tablets. The objective of this work was to present Vitamin D3 in granular and tablet form with improved dispersability, to minimize the complexity of formulations and to make cost effective product ${ }^{36,37}$.

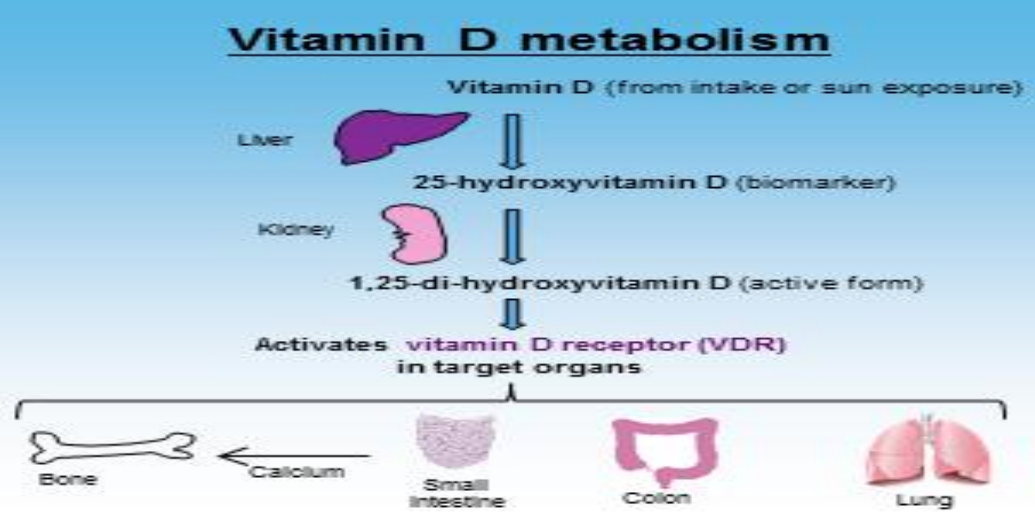

Figure :7 Vitamin D Metabolism

Coating techniques: - Generally three methods are used for tablet coating A) Sugar coating. B) Film coating. C) Enteric coating.

A) Sugar coating:

Sealing/Water proofing: provides a moisture barrier and harden the tablet surface. Sub coating causes a rapid buildup to round off the tablet edges. Grossing/Smoothing: smoothes out the sub coated surface and increases the tablet size to Predetermine dimension. Coloring gives the tablet its color and finished size. Polishing produces the characteristics gloss ${ }^{38,39}$.

B) Film coating: 
Film coating and the sugar coating share same equipment and the process parameters. There are basically 2 methods of film coating they are Pan pour methods: Tablets coated by pan pour method subjected to alternate solution application, mixing and drying steps are similar to pan pour sugar coating. This method is relatively slow and relies heavily on the skill of operator. Pan-spray methods: The introduction of spraying equipment was the next evolution in improving the film coating process allows for automated control of liquid application. Broad flat spray patterns are usually chosen by appropriate nozzle systems ${ }^{40,41}$.

Spray dryer: Spray drying is a method of producing a dry powder from a liquid or slurry by rapidly drying with a hot gas ${ }^{42,43}$. This is the preferred method of drying of many thermallysensitive materials such as foods and pharmaceuticals. A consistent particle size distribution is a reason for spray drying some industrial products such as catalysts. Air is the heated drying medium; however, if the liquid is a flammable solvent such as ethanol or the product is oxygensensitive then nitrogen is used. All spray dryers use some type of atomizer or spray nozzle to disperse the liquid or slurry into a controlled drop size spray. The most common of these are rotary disk and single-fluid high pressure swirl nozzles. Atomizer wheels are known to provide broader particle size distribution, but both methods allow for consistent distribution of particle size. Alternatively, for some applications two-fluid or ultrasonic nozzles are used. Depending on the process needs, drop sizes from 10 to $500 \mu \mathrm{m}$ can be achieved with the appropriate choices. The most common applications are in the 100 to $200 \mu \mathrm{m}$ diameter range. The dry powder is often free-flowing. The most common type of spray dryers are called single effect. There is a single source of drying air at the top of the chamber (see $n^{\circ} 4$ on the diagram). In most cases the air is blown in the same direction as the sprayed liquid (co-current). A fine powder is produced, but it can have poor flow and produce a lot of dust. To overcome the dust and poor flow of the powder, a new generation of spray dryers called multiple effect spray dryers have been produced 44 . 


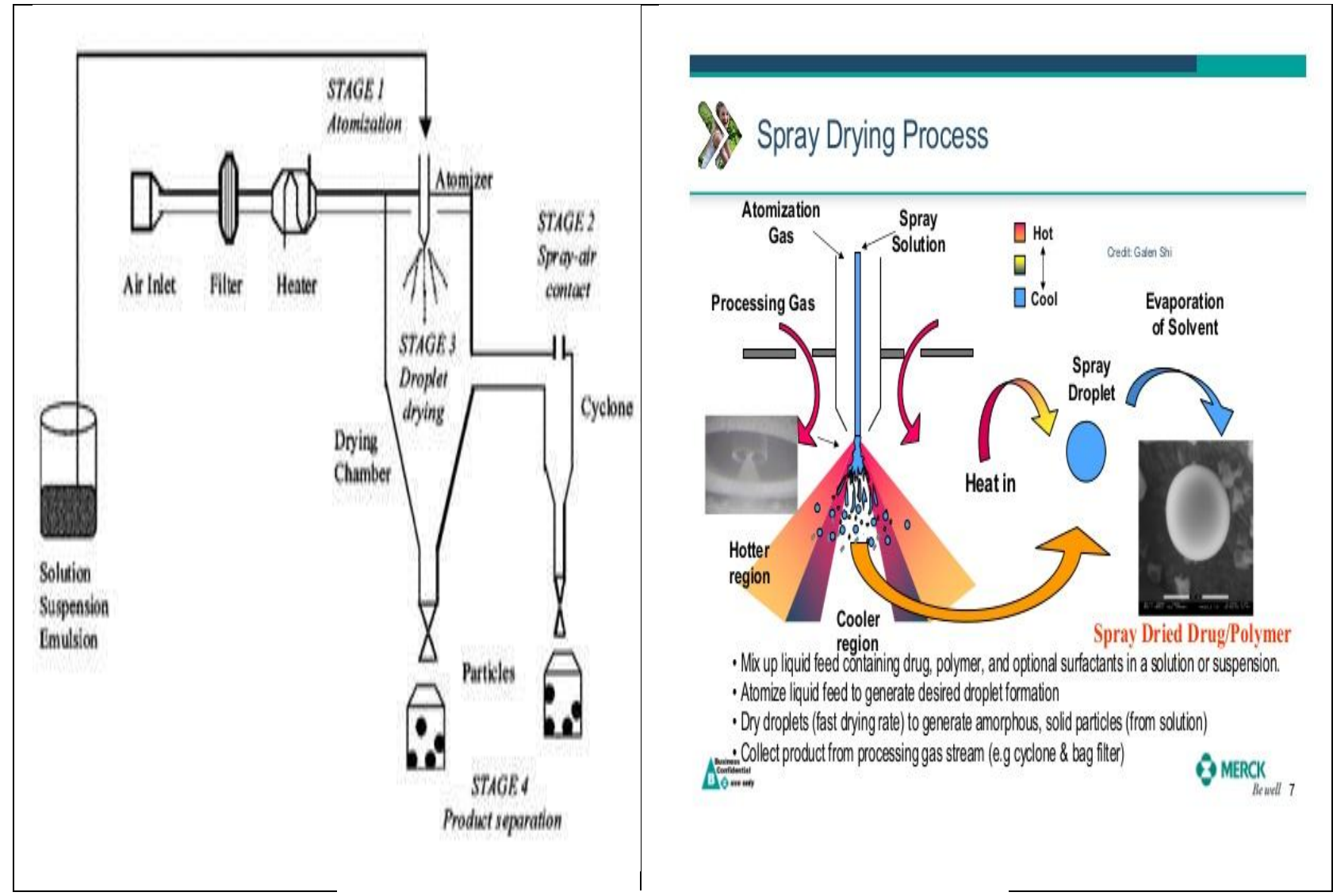

Figure :8 Tablet Compression and Formulation

\section{Encapsulation method:}

Encapsulation relates to technologies which enable to formulate one active compound (or more), inside individualized particles with a specific geometry and properties. Encapsulation defines no size notion - Microencapsulation usually refers to sizes ranging from $1 \mu \mathrm{m}$ to $1 \mathrm{~mm} \cdot$ Nanoencapsulation is used for nanometric sizes but sometimes refers to sizes ranging up to $1 \mu \mathrm{m}$ or few micrometers. Methods: droplet extrusion (single or multi nozzle device, simple gravity, spinning disk, jet breakage systems, co-extrusion) of a (bio)polymer solution in a gelation bath or in ambient/cold air ${ }^{45,46,47}$. Particles properties (standard): Size range: from $50 \mu \mathrm{m}$ to $7-8 \mathrm{~mm}$, Final state: wet (can be dried or lyophilized), Active type: liquid, solid; hydrophilic or lipophilic, Active content: up to $400 \mathrm{mg} / \mathrm{g}$ (wet), $900 \mathrm{mg} / \mathrm{g}$ (dry), Structure: matrix, core / shell (s), (matrix core) / shell ${ }^{48}$. 

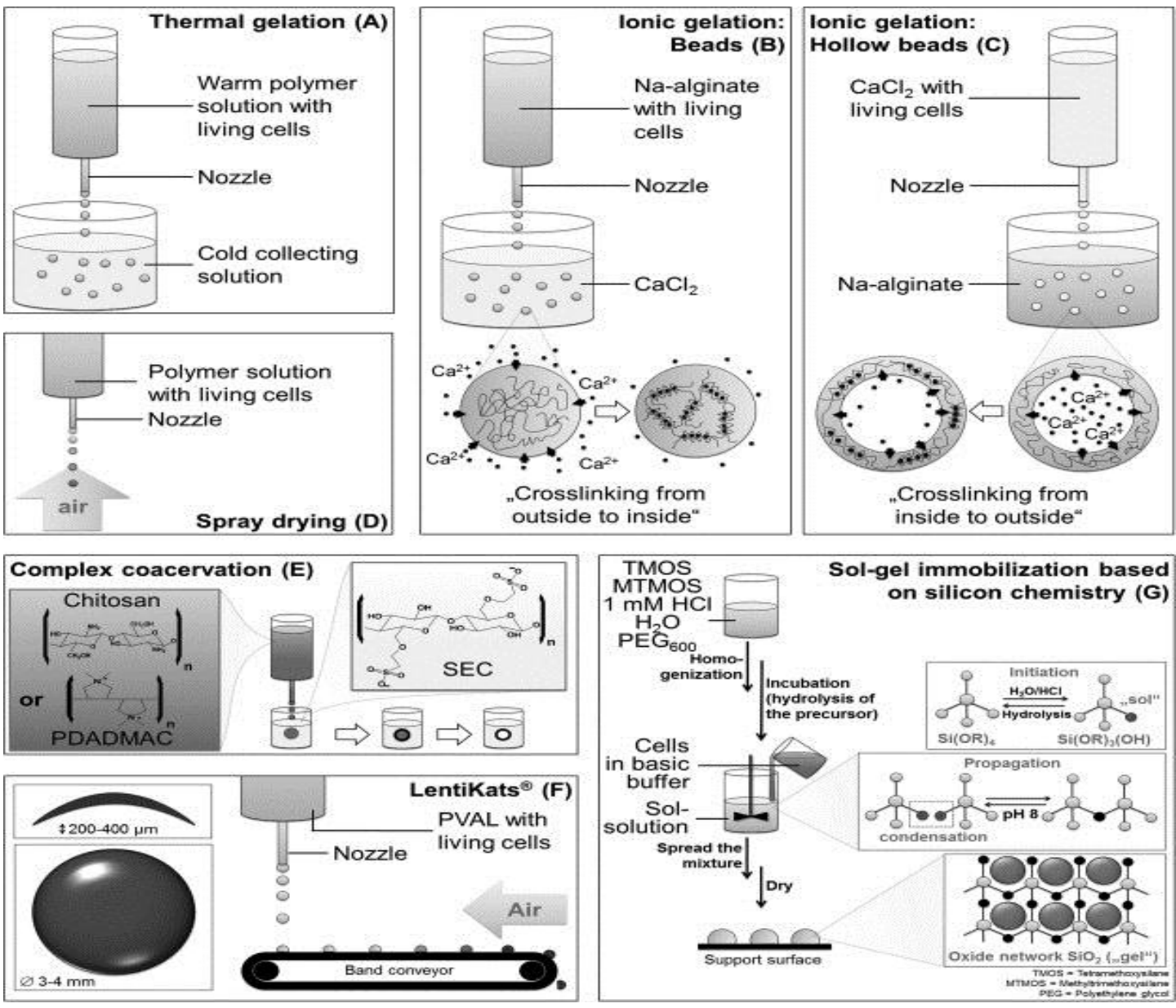

Figure :9 Hydrogenation Method

Hydrogenation - to treat with hydrogen - is a chemical reaction between molecular hydrogen $\left(\mathrm{H}_{2}\right)$ and another compound or element, usually in the presence of a catalyst such as nickel, palladium or platinum. The process is commonly employed to reduce or saturate organic compounds. Catalytic hydrogenation has evolved into a key process technology for the manufacture of pharmaceutical and fine chemicals, replacing chemical reduction methods that generate large quantities of waste. According to Roessler [1•], 10 to 20\% of chemical reactions in fine chemical synthesis at Roche are catalytic hydrogenations. Catalytic hydrogenations strike a balance among reaction kinetics, reactor design, catalyst activity and selectivity, process control, mass transfer and mixing. Each of these factors contribute to the performance of hydrogenation processes and their products ${ }^{49,50,51,52}$. 


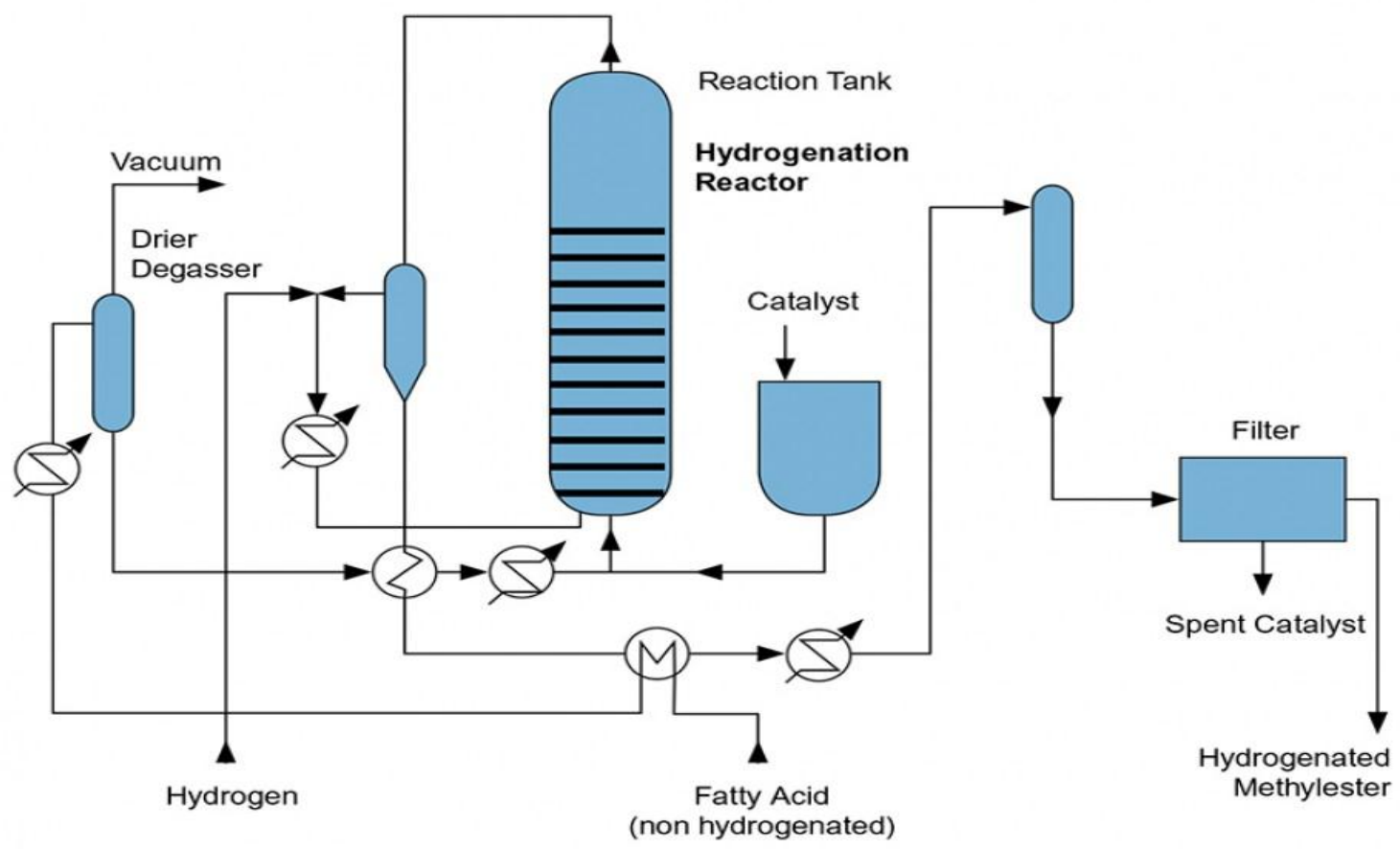

Figure :10 Continuous Hydrogenation

\section{CONCLUSION:}

Tablet in tablet is improved beneficial technology to overcome the limitation of the single layered tablet. Bi-layer tablet is suitable for sequential release of two drugs in combination of vitamin D3, separate two incompatible substances and also for sustained release tablet in which one layer is immediate release as initial dose and second layer is maintenance dose. The preparation of tablets in the form of multi layers is used to provide systems for the administration of drugs, which are incompatible and to provide controlled release tablet preparations by providing surrounding or multiple swelling layers. To developed techniques promote the new formulation overcome the supplementary like vitamin D3 tablets. Finally explains why many different types of presses are being used to produce tablet in tablets, ranging from simple singlesided presses to highly sophisticated machines.

\section{REFERENCES}

1. Grimnes G, Emaus N, Cashman KD, Jorde R. The effect of high-dose vitamin D supplementation on muscular function and quality of life in postmenopausal women-a randomized controlled trial. Clinical endocrinology. 2017 Jul 1. 
2. Bennett KA, Hybart R, Simpson CL. Differential Effects of Calcitriol, FGF-23, and Klotho on Vascular Smooth Muscle Cell Calcification and Their Role in Medial Calcification. Volume 62 October 2017 Number 4. 2017 Oct;62(4):370.

3. Okazaki R, Ozono K, Fukumoto S, Inoue D, Yamauchi M, Minagawa M, Michigami T, Takeuchi Y, Matsumoto T, Sugimoto T. Assessment criteria for vitamin D deficiency/insufficiency in Japan: proposal by an expert panel supported by the Research Program of Intractable Diseases, Ministry of Health, Labour and Welfare, Japan, the Japanese Society for Bone and Mineral Research and the Japan Endocrine Society [Opinion]. Journal of bone and mineral metabolism. 2017 Jan 1;35(1):1-5.

4. Bohlke K. The Importance of Exercise Before and After a Cancer Diagnosis. group. 2018 Jan 15.

5. Mayfield E. With research pointing to pros and cons of vitamin and mineral supplements, these dietary decisions become increasingly complex. group. 2018 Jan 22.

6. Schwab J, Popovich P, Rezai AR, inventors; Ohio State Innovation Foundation, assignee. Systems and methods of improving an immune disorder. United States patent application US 15/382,911. 2017 Apr 13.

7. Berridge MJ. Vitamin D and depression: cellular and regulatory mechanisms. Pharmacological reviews. 2017 Apr 1;69(2):80-92.

8. Khaled SA, Alexander MR, Wildman RD, Wallace MJ, Sharpe S, Yoo J, Roberts CJ. 3D extrusion printing of high drug loading immediate release paracetamol tablets. International Journal of Pharmaceutics. 2018 Jan 17.

9. Navya D, Deepika B, Regupathi T. Formulation Development And Evaluation Of Bilayered Buccal Tablets Of Ramipril. Innovat International Journal Of Medical \& Pharmaceutical Sciences. 2017 Dec 1;2(7).

10. Ritschel WA. Peroral solid dosage forms with prolonged action. Drug Design. 2017 Jun $29 ; 4: 37-73$.

11. Pavani J, Deepika B, Nagaraju K, Regupathi T, Rao KN, Dutt KR. Formulation Development And In Vitro Evaluation Of Sustained Release Matrix Tablets Of Tramadol Hydrochloride. Innovat International Journal Of Medical \& Pharmaceutical Sciences. 2017 Dec 1;2(7).

12. Pundir S, Badola A, Sharma D. Sustained release matrix technology and recent advance in matrix drug delivery system: a review. International Journal of drug research and technology. 2017 Feb 28;3(1):8. 
13. Peirce C, Ippolito S, Lanas A, Pesce M, Pontieri G, Arpaia D, Sarnelli G, Biondi B. Treatment of refractory and severe hypothyroidism with sublingual levothyroxine in liquid formulation. Endocrine. 2018 Apr 1;60(1):193-6.

14. Chono S, Nakamura K, Matsui M. Physical properties of lansoprazole orally disintegrating tablets. Journal of Generic Medicines. 2017 Mar;13(1):5-8.

15. Silberstein SD. A review of clinical safety data for sumatriptan nasal powder administered by a breath powered exhalation delivery system in the acute treatment of migraine. Expert opinion on drug safety. 2018 Jan 2;17(1):89-97.

16. Fonseca RJ, Sucupira ID, Oliveira SN, Santos GR, Mourão PA. Improved anticoagulant effect of fucosylated chondroitin sulfate orally administered as gastroresistant tablets. Thrombosis and haemostasis. 2017 Apr;117(04):662-70.

17. Srikanth A, Reddy KN, Kanchanamala K. Formulation and evaluation of floating tablets of Tapentadol $\mathrm{HCl}$ by direct compression method by using different swellable polymers and effervescent agents. Indian Journal of Research in Pharmacy and Biotechnology. 2017 Mar 1;5(2):145.

18. Hayward MA, Schmidt T, inventors; Effrx Pharmaceuticals Sa, assignee. Stable effervescent bisphosphonate formulations with rapid solubilization characteristics. United States patent US 9,592,195. 2017 Mar 14.

19. Li Q, Wen H, Jia D, Guan X, Pan H, Yang Y, Yu S, Zhu Z, Xiang R, Pan W. Preparation and investigation of controlled-release glipizide novel oral device with three-dimensional printing. International journal of pharmaceutics. 2017 Jun 15;525(1):5-11.

20. Cetinkaya C, inventor; Clarkson University, assignee. Methods and systems for in-and out-of-die monitoring and characterization of multi-component tablets and for detecting and monitoring stiction and tooling material modifications on punch and die surfaces. United States patent US 9,739,753. 2017 Aug 22.

21. Seshadri VC, Manohari PJ, Kunchithapatham J, Rama A, Ramalingam S. Formulation And Evaluation Of Pulsatile Delivery System Of Zolpidem tartrate.

22. Qiu Y, He X, Zhu L, Chen B. Product and Process Development of Solid Oral Dosage Forms. InDeveloping Solid Oral Dosage Forms (Second Edition) 2017 (pp. 555-591).

23. Alinaghian L, Razmdoost K. How do network resources affect firms' network-oriented dynamic capabilities?. Industrial Marketing Management. 2017 Dec 19.

24. Aulton ME. Powders, granules and granulation. Aulton's Pharmaceutics E-Book: The Design and Manufacture of Medicines. 2017 Aug 26:476. 
25. Reddy MR, Sulthana A, Reddy AJ, Kumar PK. An overview on novel trends in orally mouth dissolving tablet.

26. Gupta AM, Shivhare UD, Suruse PB. Different Aspects of Pellets Formulation and their Evaluation. International Journal of Pharmaceutical and Phytopharmacological Research. 2017 Mar 22;4(6):331-6.

27. Puri V, Brancazio D, Harinath E, Martinez AR, Desai PM, Jensen KD, Chun JH, Braatz RD, Myerson AS, Trout BL. Demonstration of pharmaceutical tablet coating process by injection molding technology. International journal of pharmaceutics. 2018 Jan 15;535(1):106-12.

28. Desai PM, Puri V, Brancazio D, Halkude BS, Hartman JE, Wahane AV, Martinez AR, Jensen KD, Harinath E, Braatz RD, Chun JH. tablet coating by injection molding technology-Optimization of coating formulation attributes and coating process parameters. European Journal of Pharmaceutics and Biopharmaceutics. 2018 Jan 1;122:25-36.

29. Tang Y, Teng H, Shi Y, He H, Zhang Y, Yin T, Cai C, Tang X. Tablets of paliperidone using compression-coated technology for controlled ascending release. Asian Journal of Pharmaceutical Sciences. 2017 Oct 13.

30. Parveen S, Khinchi MP, Dubey CK, Sharma P. RECENT ADVANCEMENT IN TABLET COATING TECHNOLOGY.

31. Jones FN, Nichols ME, Pappas SP. Organic coatings: science and technology. John Wiley \& Sons; 2017 Oct 2.

32. Porter S, Sackett G, Liu L. Development, optimization, and scale-up of process parameters: pan coating. In Developing Solid Oral Dosage Forms (Second Edition) 2017 (pp. 953-996).

33. Hamman H, Hamman J, Steenekamp J. Multiple-Unit Pellet Systems (MUPS): Production and Applications as Advanced Drug Delivery Systems. Drug Delivery Letters. 2017 Dec 1;7(3):201-10.

34. Agarwal S. Modeling the Scaling of Intra-Tablet Coating Variability (Doctoral dissertation, Purdue University).

35. Niblett D, Porter S, Reynolds G, Morgan T, Greenamoyer J, Hach R, Sido S, Karan K, Gabbott I. Development and evaluation of a dimensionless mechanistic pan coating model for the prediction of coated tablet appearance. International journal of pharmaceutics. 2017 Aug 7;528(1-2):180-201. 
36. Sokal A, Pindelska E, Szeleszczuk L, Kolodziejski W. Pharmaceutical properties of two ethenzamide-gentisic acid cocrystal polymorphs: Drug release profiles, spectroscopic studies and theoretical calculations. International journal of pharmaceutics. 2017 Apr 30;522(1-2):80-9.

37. Chomto P, Nunthanid J. Physicochemical and powder characteristics of various citrus pectins and their application for oral pharmaceutical tablets. Carbohydrate polymers. 2017 Oct 15;174:25-31.

38. Mishra A, Bhatt GK, Kothiyal P. Bilayer tablet and evaluation. International journal of drug research and technology. 2017 Feb 28;3(2):9.

39. Sacchetti M, Teerakapibal R, Kim K, Elder EJ. Role of water sorption in tablet crushing strength, disintegration, and dissolution. AAPS PharmSciTech. 2017 Aug 1;18(6):221426.

40. Chen W, Wang J, Desai D, Chang SY, Kiang S, Lyngberg O. A Strategy for Tablet Active Film Coating Formulation Development Using a Content Uniformity Model and Quality by Design Principles. Comprehensive Quality by Design for Pharmaceutical Product Development and Manufacture. 2017 Aug 30:193-233.

41. Ketterhagen W, Aliseda A, am Ende M, Berchielli A, Doshi P, Freireich B, Prpich A. Modeling tablet film-coating processes. InPredictive Modeling of Pharmaceutical Unit Operations 2017 (pp. 273-316).

42. Popplewell LM, Hans KT, Henson L, Lavallee CT, Wolff EJ, Wright M, inventors; International Flavors, Fragrances Inc, assignee. Spray-dried compositions capable of retaining volatile compounds and methods of producing the same. United States patent application US 15/722,465. 2018 Feb 1.

43. Rahaman MN. Ceramic processing. CRC press; 2017 Jul 4.

44. Bardosh W, McKenzie RR, Mekonnen T, Nerkar MG, Miazga-Rodriguez M, inventors; Terraverdae Bioworks Inc., assignee. Bioactive biopolymer films and coatings. United States patent application US 15/487,837.2017 Aug 31.

45. Viovy JL, Chabert M, inventors. Encapsulation microfluidic device. United States patent US 9,744,513. 2017 Aug 29.

46. Sum TC, Chen W, Mhaisalkar SG, Mathews N, Veldhuis SA, Bhaumik S, inventors; Nanyang Technological University of Singapore, assignee. Perovskite core-shell nanocrystals. United States patent application US 15/637,385. 2018 Jan 4. 
47. Ulloa PA, Guarda A, Valenzuela X, Rubilar JF, Galotto MJ. Modeling the release of antimicrobial agents (thymol and carvacrol) from two different encapsulation materials. Food Science and Biotechnology. 2017 Dec 1;26(6):1763-72.

48. Sheldon RA, Woodley JM. Role of biocatalysis in sustainable chemistry. Chemical reviews. 2017 Sep 6.

49. Cornils B, Herrmann WA, Beller M, Paciello R, editors. Applied Homogeneous Catalysis with Organometallic Compounds: A Comprehensive Handbook in Four Volumes. John Wiley \& Sons; 2018 Jan 4.

50. Rajurkar KB. Studies in catalysis and reaction engineering aspects of multiphase catalytic reactions (Doctoral dissertation).

51. da Paz JA, Sales A, da Silva LD, da Silva ÉF, da Costa JA, Navarro M, de Menezes FD, Vilar M. Ultrasound-assisted electrocatalytic hydrogenation in water. Applied Catalysis A: General. 2018 Jan 25;550:245-55.

52. Shylesh S, Gokhale AA, Ho CR, Bell AT. Novel Strategies for the Production of Fuels, Lubricants, and Chemicals from Biomass. Accounts of chemical research. 2017 Sep 20;50(10):2589-97. 